\title{
EFEITOS DE TEMPOS E TEMPERATURAS DE CONDICIONAMENTO SOBRE A QUALIDADE FISIOLÓGICA DE SEMENTES DE CAFEEIRO (Coffea arabica, L.) SOB CONDIÇÕES IDEAIS E DE ESTRESSE TÉRMICO
}

\author{
Effects of the times and temperatures of conditioning on the physiological \\ quality of coffee seeds (Coffea arabica $\mathbf{L}$.) under ideal conditions and under thermal stress
}

\author{
Sílvia Mara Pacheco Lima ${ }^{1}$, Renato Mendes Guimarães ${ }^{2}$, \\ João Almir Oliveira ${ }^{2}$, Maria das Graças Guimarães Carvalho Vieira ${ }^{2}$
}

\section{RESUMO}

Objetivou-se com a presente pesquisa estudar tempos e temperaturas mais adequadas para o condicionamento fisiológico e avaliar os efeitos desses tratamentos na germinação sob condições de estresse térmico, de sementes de cafeeiro armazenadas. O estudo foi conduzido nos Laboratórios de Análise de Sementes e Técnicas Moleculares do Departamento de Agricultura da Universidade Federal de Lavras, utilizando-se sementes de café da cultivar Acaiá do cerrado. As sementes foram colhidas nos campos de produção da UFLA e armazenadas em condições de ambiente de agosto/2000 a janeiro/2001, quando foram submetidas ao condicionamento em água nas temperaturas de 15,25 e $35^{\circ} \mathrm{C}$ por 4,812 dias de embebição. O condicionamento foi realizado em câmara tipo BOD, na presença de luz, e a aeração foi feita com compressores e bombas de aquário. Após cada tratamento, as sementes foram imediatamente submetidas à determinação do teor de água e avaliadas pelos testes de germinação e índice de velocidade de germinação sob estresse térmico $\left(20\right.$ e $\left.35^{\circ} \mathrm{C}\right)$ e eletroforese de enzimas. Para comparação, foram utilizadas sementes sem tratamento de embebição. Pelos resultados, conclui-se que as sementes condicionadas em água a 15 e $25^{\circ} \mathrm{C}$ apresentaram melhor desempenho da germinação em condições de estresse térmico; o condicionamento a $35^{\circ} \mathrm{C}$ não foi apropriado; o condicionamento por 4 dias foi o menos eficiente em melhorar a qualidade fisiológica das sementes, e o condicionamento fisiológico em água mostrou-se eficaz ao revigoramento, principalmente a $25^{\circ} \mathrm{C}$ por 12 dias.

Termos para indexação: Condicionamento fisiológico, sementes, café, germinação.

\begin{abstract}
The goal of this work was the evaluation of the adequate times and temperatures for the physiological contitioning and effects of this techinique in the germination on stress conditions, of stored coffee seeds. The experiment was performed in the Seed and Molecular Techniques Laboratories of the UFLA's Agriculture Departament. The seeds used were from the cultivar Acaiá Cerrado. The seeds were harvested in the coffee seed production fields at UFLA and stored at room temperature from August/2000 to January/2001, when they were submitted to physiological conditioning under temperatures of 15,25 and $35^{\circ} \mathrm{C}$ for 4,8 and 12 days of imbibitions in water. The conditioning was dosse in BOD chambers in presence of light and the air was pumped using small aquarium pumps and compressors. After each treatment the seeds were imediately submitted to the determination of the water content and evaluated through the germination and germination speed tests under thermal stress $(20$ and $35^{\circ} \mathrm{C}$ ) and enzymes eletrophoresis. Seeds without the imbibing treatment were used as control. It was conclued that the water conditioning at 15 and $25^{\circ} \mathrm{C}$ was efficient in increasing the germination and vigor of coffee seeds under thermal stress conditions, the conditioning at $35^{\circ} \mathrm{C}$ was not apropriated, the conditioning for four days was the least efficient treatment in improving the physiological quality of seeds, and the physiological conditioning in water was efficient in recovering the vigor, specially at $25^{\circ} \mathrm{C}$ for 12 days.
\end{abstract}

Index Terms: Physilogical conditioning, seeds, coffee, germination.

(Recebido para publicação em $1^{\circ}$ de julho de 2002 e aprovado em 13 de novembro de 2002)

\section{INTRODUÇÃO}

Durante a germinação de sementes, a fase mais crítica é representada pelo período compreendido entre a semeadura e a emergência de plântulas. Nesse perío do, as condições ambientais podem não ser adequadas, ocorrendo freqüentes estresses físicos, tais como temperaturas supra-ótimas, excesso ou deficiência de água. 
A propagação do cafeeiro é feita por mudas oriundas de sementes; portanto, o uso de sementes de boa qualidade é o fator condicionante da produção. Sementes de café são reconhecidamente de difícil conservação, mantendo a viabilidade por, no máximo, seis meses, quando armazenadas em condições normais de ambiente. Além disso, germinam lentamente, podendo levar até 90 dias; no período frio do ano pode levar até 120 dias (WENT, 1957). Dessa maneira, tratamentos realizados antes da semeadura, visando a melhorar o desempenho germinativo das sementes são desejáveis. A tentativa de desenvolver técnicas para acelerar a germinação e, consequientemente, a formação de mudas é de grande importância para a cafeicultura, pois poderia permitir um semeio em época mais adequada, possibilitando um plantio mais cedo, no início da estação chuvosa. A técnica de condicionamento fisiológico de sementes vem sendo bastante estudada em diversas espécies e tem se destacado entre os tratamentos prégerminativos em sementes de cafeeiro. Segundo Heydecker et al. (1975), a utilização da técnica de condicionamento fisiológico é muito útil para obter germinação mais rápida, emergência precoce das plântulas, germinação sincronizada e possibilidade de capacitar as sementes a germinar em temperaturas subótimas. Também Khan (1976) ressaltou que o condicionamento fisiológico pode promover efeitos benéficos no desempenho de sementes, incluindo a redução no tempo de emergência, uniformidade na emergência, aumento no sistema radicular e proteção fisiológica das sementes contra condições adversas do meio. A hidratação das sementes pode ser feita pela embebição direta em água e em soluções osmóticas ou, ainda, envolver um ou mais ciclos de hidratação-secagem. Em sementes de cafeeiro, o método de hidratação das sementes pela imersão direta em água tem se mostrado bastante promissor (CAMARGO, 1998; LIMA, 1999). Cabe ressaltar ainda que uma melhoria no desempenho germinativo poderia diminuir o gasto com sementes e, principalmente, permitir a utilização de sementes de cafeeiro armazenadas. Assim, conduziu-se esta pesquisa com o objetivo de avaliar os efeitos de temperaturas e tempos de condicionamento fisiológico em sementes de cafeeiro sobre a germinação e o vigor.

\section{MATERIAL E MÉTODOS}

O trabalho foi desenvolvido no Laboratório de Análise de Sementes e Técnicas Moleculares do Departamento de Agricultura da Universidade Federal de Lavras (MG) e Laboratório de Análises Bioquímicas da EPAMIG, utilizando-se sementes de cafeeiro da cultivar Acaiá do Cerrado, proveniente da safra 2000, colhidas nos campos de produção de sementes da UFLA. As sementes permaneceram armazenadas em condições de ambiente de agosto/2000 a janeiro/2001, quando foram iniciados os testes.

As sementes foram selecionadas, eliminando-se aquelas malformadas e quebradas e, em seguida, o endocarpo (pergaminho) foi retirado pelo processo manual. Por ocasião da instalação dos testes, as sementes encontravam-se com uma viabilidade inicial de 59\%, determinada pelo teste de tetrazólio e umidade de $11,04 \%$, determinada pelo método de estufa $\left(105^{\circ} \mathrm{C} \pm\right.$ $3^{\circ} \mathrm{C}$ por 24 horas), conforme prescrições das Regras para Análise de Sementes (BRASIL, 1992).

\section{Condicionamento fisiológico em diferentes tempos e temperaturas}

As sementes foram submersas em água no interior de três recipientes plásticos com capacidade de 3 litros, de modo que o nível da água sobrepunha o nível das sementes. Cada recipiente foi colocado no interior de câmaras tipo BOD, na presença de luz e temperaturas de 15,25 e $35^{\circ} \mathrm{C}$ cada um. A aeração foi realizada durante todo o período de condicionamento $(4,8$ e 12 dias) por meio de injeção de ar com compressor para aquário e com uma bomba especial para filtro de aquário (Whisper-Power filtrer), que promovia a circulação da água que caía em forma de uma cascata.

Decorridos 4, 8 e 12 dias de embebição, as sementes foram retiradas e submetidas às avaliações. Simultaneamente, como testemunha, foram avaliadas as sementes não-condicionadas.

\section{Determinação do grau de umidade}

Foram tomadas duas repetições de aproximadamente $10 \mathrm{~g}$ de sementes, que foram colocadas em recipientes de alumínio (diâmetro de $4 \mathrm{~cm}$ ), pesadas e secas a $105^{\circ} \mathrm{C} \pm 3^{\circ} \mathrm{C}$ por 24 horas, conforme as $\mathrm{Re}$ gras para Análise de Sementes (BRASIL, 1992). Os resultados foram expressos em porcentagem.

\section{Índice de velocidade de germinação sob con- dições ideais de temperatura}

Foi conduzido com quatro repetições de 50 sementes, dispostas em dois rolos de 25 sementes cada um para cada tratamento. O substrato utilizado foi o rolo de papel-toalha umedecido com água na proporção de 2,5 vezes o peso do papel. As sementes permaneceram em germinador a $30^{\circ} \mathrm{C}$, na presença de 
luz. As contagens do número de sementes germinadas (protusão radicular de no mínimo $1 \mathrm{~mm}$ de comprimento) foram realizadas a cada três dias, até a completa estabilização do estande. Posteriormente, foi calculado o índice de velocidade de germinação, de acordo com a fórmula de Maguirre (1962):

$$
\operatorname{IVPR}=\frac{\mathrm{G}_{1}}{\mathrm{~N}_{1}}+\frac{\mathrm{G}_{2}}{\mathrm{~N}_{2}}+\ldots+\frac{\mathrm{G}_{\mathrm{n}}}{\mathrm{N}_{\mathrm{n}}}
$$

Em que:

IVPR = índice de velocidade de protusão radicular;

$\mathrm{G}_{1}, \mathrm{G}_{2}, \ldots \mathrm{G}_{\mathrm{n}}=$ número de sementes com radículas emergidas, computadas na primeira contagem, segunda contagem, ..., última contagem;

$\mathrm{N}_{1}, \mathrm{~N}_{2}, \ldots, \mathrm{N}_{\mathrm{n}}=$ número de dias da semeadura à primeira, segunda, ..., última contagem.

\section{Índice de velocidade de germinação sob con- dições de estresse térmico}

A metodologia utilizada foi semelhante à descrita no item anterior, porém, em câmaras reguladas a $20^{\circ} \mathrm{C}$ e $35^{\circ} \mathrm{C}$.

\section{Análise eletroforética}

Ao final de cada tratamento, procedeu-se à extração de embriões de 200 sementes, e para extrair os embriões da testemunha (sementes nãocondicionadas), as sementes foram embebidas em água destilada por 24 horas para facilitar a extração. À medida que eram extraídos, os embriões foram colocados em microtubos contendo antioxidante (PVP 40 ). Ao final da extração, os microtubos contendo os embriões foram imediatamente congelados por submersão em nitrogênio líquido por 15 segundos e mantidos em deep-freezer a $-86^{\circ} \mathrm{C}$. No momento da extração, os embriões de cada tratamento foram triturados em mortar na presença de nitrogênio líquido.

A extração das enzimas foi efetuada adicionando-se a $100 \mathrm{mg}$ do pó dos embriões $250 \mu \mathrm{L}$ do tampão de extração $(0,2 \mathrm{M}$ Tris, $\mathrm{pH} 8,0,0,1 \%$ mercaptoetanol, 0,4\% PVP, 0,4\% PEG, 1mM EDTA). O homogeneizado foi incubado em gelo por 2 horas e centrifugado a $16000 \mathrm{xg} \mathrm{a} 4^{\circ} \mathrm{C}$ por 60 minutos. Posteriormente, $60 \mu \mathrm{L}$ do sobrenadante de cada tratamento foram aplicados nos géis de poliacrilamida a 4,5\% (gel concentrador) e 7,5\% (gel separador). As corridas eletroforéticas foram desenvolvidas a $150 \mathrm{~V}$ por cerca de quatro horas. Após a migração eletroforética, os géis foram revelados para álcool desidrogenase $(\mathrm{ADH})$ e isocitrato desidrogenase (IDH), de acordo com metodologia descrita por Alfenas (1991).

\section{RESULTADOS E DISCUSSÂO}

\section{Grau de umidade das sementes}

Verifica-se nas sementes condicionadas a 15 , 25 e $35^{\circ} \mathrm{C}$ uma tendência crescente ao longo do período de condicionamento, e aquelas condicionadas à temperatura de $35^{\circ} \mathrm{C}$ atingiram um patamar de umidade mais elevado aos 4 e 8 dias de condicionamento. Já aos 12 dias de embebição, houve uma tendência a igualar os graus de umidade das sementes, independente das temperaturas de condicionamento (Figura 1a).

Pela Figura 1b, na qual está apresentado o comportamento do grau de umidade das sementes em função da temperatura de condicionamento, verifica-se também uma tendência crescente da umidade à medida que a temperatura aumenta. Pode-se verificar ainda no tempo de 4 dias de embebição um patamar de umidade mais reduzido, o que pode ser justificado por ser esse o menor tempo estudado, mostrando, dessa maneira, que as sementes continuaram absorvendo água até os 12 dias. Deve-se ressaltar que os teores de água das sementes, após os tratamentos de condicionamento, foram significativamente superiores ao da testemunha, que se apresentava inicialmente com teor de água de $11,04 \%$.

A absorção de água pelas sementes é caracterizada como sendo um processo altamente condicionado às propriedades físico-químicas, controladas pelas propriedades da água. Dessa forma, a embebição está relacionada com as propriedades dos colóides, sofrendo influência das condições ambientais e da composição do solvente que afeta a velocidade do processo (LABOURIAU, 1983). Assim, a falta de um agente restritor da embebição neste estudo possibilitou grandes ganhos de umidade logo no início do processo de embebição, quando as sementes foram condicionadas por 4 dias, principalmente à temperatura de $35^{\circ} \mathrm{C}$.

Índice de velocidade de germinação sob condição térmica de $30^{\circ} \mathrm{C}$

Verifica-se pela Figura 2a uma tendência linear decrescente do índice quando as sementes foram condicionadas a $25^{\circ} \mathrm{C}$ e a $35^{\circ} \mathrm{C}$ no decorrer do tempo de embebição, sendo os mais baixos valores de índice ob- 
servados no tempo de 12 dias. Por outro lado, analisando o comportamento desse índice nas sementes condicionadas a $15^{\circ} \mathrm{C}$, verifica-se uma tendência crescente até o período de tempo de 8 dias, seguido de uma tendência decrescente até aos 12 dias. Observa-se ainda que os menores índices foram obtidos nas sementes condicionadas a $35^{\circ} \mathrm{C}$, independente do tempo de embebição. Já, na Figura $2 b$, na qual estão apresentados os índices de velocidade de germinação sob condição térmica de $30^{\circ} \mathrm{C}$ em função da temperatura de condicionamento, verifica-se que os maiores índices foram encontrados nas sementes embebidas por um período de 4 dias a $25^{\circ} \mathrm{C}$ e a $35^{\circ} \mathrm{C}$, ao passo que, à temperatura de $15^{\circ} \mathrm{C}$, os tempos de 4 e 8 dias apresentaram índices bastante próximos. Com relação ao tempo de embebição correspondente a 12 dias, foram verificados os meno- res índices em todas as temperaturas de condicionamento estudadas.

A comparação da testemunha com os diferentes tratamentos está apresentada na Figura 5. Verifica-se um efeito negativo quando as sementes foram condicionadas a $35^{\circ} \mathrm{C}$ por 8 e 12 dias. Por outro lado, o maior índice foi obtido nas sementes embebidas por 4 dias à temperatura de $25^{\circ} \mathrm{C}$, enquanto os demais tratamentos propiciaram índices estatisticamente semelhantes à testemunha. De acordo com Nascimento (1998), a temperatura utilizada para o condicionamento fisiológico geralmente é aquela recomendada para a germinação das sementes, a qual, com algumas exceções, varia entre 15 e $25^{\circ} \mathrm{C}$. Por outro lado, segundo Gulliver e Heydecker (1973) temperaturas elevadas durante o condicionamento fisiológico podem prejudicar a qualidade das sementes. $\mathbf{a}$

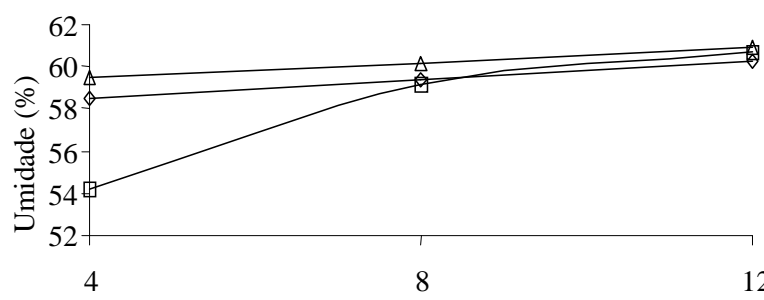

Tempo de embebição (dias)

$$
\neg-15 \text { graus } \diamond-25 \text { graus } \triangleleft 35 \text { graus }
$$

b

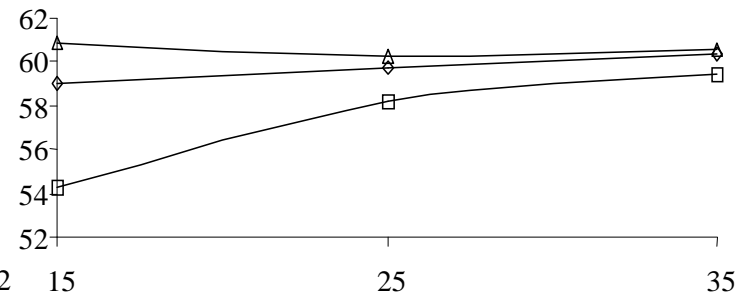

Temperatura de condicionamento

$\square-4$ dias $\multimap-8$ dias $\triangle 12$ dias

FIGURA 1 - Estimativa do grau de umidade (\%) de sementes de cafeeiro após o condicionamento fisiológico a temperaturas de 15,25 e $35^{\circ} \mathrm{C}$, por períodos de 4, 8 e 12 dias de embebição. UFLA, Lavras-MG, 2003. 

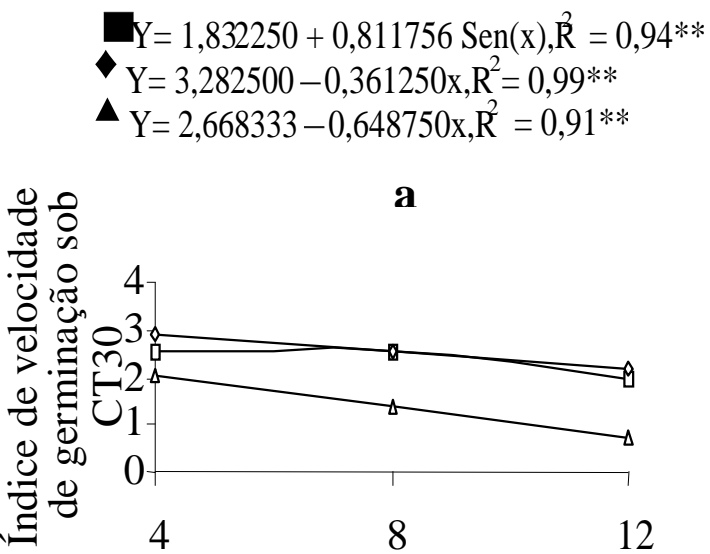

Tempo de embebição

$$
\rightarrow-15 \text { graus } \rightarrow 25 \text { graus } \rightarrow 35 \text { graus }
$$

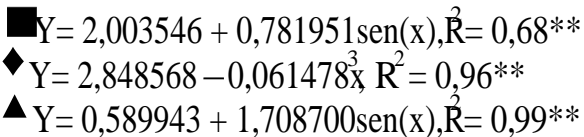

b

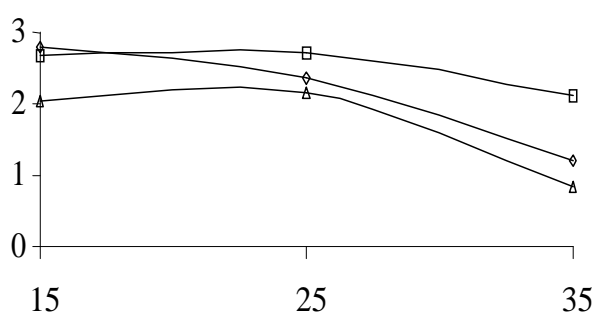

Temperatura de condicionamento

$\rightarrow 4$ dias $\rightarrow 8$ dias $\rightarrow 12$ dias

FIGURA 2 - Índice de velocidade de germinação sob condições térmicas de $30^{\circ} \mathrm{C}$ (CT30) de sementes de cafeeiro submetidas ao condicionamento fisiológico em diferentes temperaturas e períodos de tempo. UFLA, Lavras-MG, 2003.

\section{Índice de velocidade de germinação sob es- tresse térmico}

\section{Estresse térmico a $20^{\circ} \mathrm{C}$}

Observando os resultados da Figura 3a, na qual é apresentado o índice de velocidade de germinação sob estresse térmico de $20^{\circ} \mathrm{C}$, é possível verificar uma tendência linear decrescente ao longo do tempo de embebição, quando as sementes foram condicionadas nas temperaturas de $15^{\circ} \mathrm{C}$ e $35^{\circ} \mathrm{C}$. Observa-se também que à temperatura de $35^{\circ} \mathrm{C}$ ocorreram os menores índices em todos os tempos de embebição. Vale ressaltar que as sementes condicionadas a $35^{\circ} \mathrm{C}$, além da coloração escura observada ao final dos tratamentos, ao serem colocadas para germinar, apresentaram uma mortalidade de quase $100 \%$ na última contagem do teste. Esse fato nos demonstra que essa temperatura não deve ser utilizada para o condicionamento de sementes de cafeeiro, possivelmente por acelerar a respiração e, conseqüentemente, o processo de deterioração das sementes. Por outro lado, quando as sementes foram condicionadas a $25^{\circ} \mathrm{C}$, o índice de velocidade de germinação sob estresse térmico de $20^{\circ} \mathrm{C}$ foi superior ao das demais temperaturas de condicionamento, porém, bastante próximo aos índices obtidos das sementes embebidas a $15^{\circ} \mathrm{C}$. Na Figura $3 \mathrm{~b}$, na qual está apresentado o índice de velocidade de germinação sob estresse térmico de $20^{\circ} \mathrm{C}$ das sementes de cafeeiro condicionadas em função da temperatura, nota-se uma tendência decrescente nos tempos de 4 e 8 dias de embebição até a temperatura de $35^{\circ} \mathrm{C}$. Já, no tempo de 12 dias de embebição, foi observada uma tendência crescente até a temperatura de $25^{\circ} \mathrm{C}$, seguida de uma tendência decrescente até aos $35^{\circ} \mathrm{C}$, de modo que, em todos os tempos estudados, os menores valores de índices foram verificados nas sementes condicionadas a $35^{\circ} \mathrm{C}$.

Analisando as comparações entre a testemunha e os tratamentos de condicionamento fisiológico, observase na Figura 5 uma superioridade nos valores dos índices quando as sementes foram embebidas a $15^{\circ} \mathrm{C}$ e $25^{\circ} \mathrm{C}$, em todos os tempos de embebição estudados, demonstrando, assim, que esses tratamentos permitiram que as sementes resistissem melhor a essa condição de estresse. Na utilização prática desses resultados, a redução do tempo de exposição das sementes às adversidades do ambiente de viveiro durante a germinação pode representar ganhos significativos. $\mathrm{O}$ aumento do tempo de permanência das sementes no solo contribui para o insucesso da germinação, já que fatores, como condi- 
ções inadequadas de luminosidade, temperaturas sub ou supra-ótimas, presença de microrganismos, insetos, além de outros, podem direta ou indiretamente contribuir para a deterioração das sementes (KHAN et al., 1976, 1980/81). Por outro lado, ao se comparar os índices nas sementes condicionadas a $35^{\circ} \mathrm{C}$, verifica-se mais uma vez o efeito negativo proporcionado às sementes embebidas por 12 dias, ao passo que nos tempos de 4 e 8 dias, não foi constatada diferença significativa com relação à testemunha.

\section{Estresse térmico a $35^{\circ} \mathrm{C}$}

Pela Figura 4, na qual estão apresentados os índices de velocidade de germinação sob estresse térmico de $35^{\circ} \mathrm{C}$ das sementes de cafeeiro condicionadas a diferentes tempos e temperaturas, pode-se verificar que, de um modo geral, o tempo de 4 dias e a temperatura de $35^{\circ} \mathrm{C}$ proporcionaram os menores índices, enquanto a temperatura de $25^{\circ} \mathrm{C}$ e o tempo de 12 dias, os maiores. Verifica-se ainda pela Figura $4 \mathrm{~b}$ uma tendência linear decrescente do índice quando as sementes foram submetidas ao condicionamento por 4 dias, à medida que a temperatura aumentava, ao passo que nas sementes condicionadas por 12 dias, foi observada uma

$\nabla_{\mathrm{Y}}=2,193333-0,016250 \mathrm{x}, \mathrm{R}^{2}=0,99 * *$

$\mathrm{Y}=2,306388+0,067080 \operatorname{Tan}(\mathrm{x}), \mathrm{R}^{2}=0,59 * *$

$\mathrm{Y}=2,405833-0,560000 \mathrm{x}, \mathrm{A}^{2}=0,99 * *$

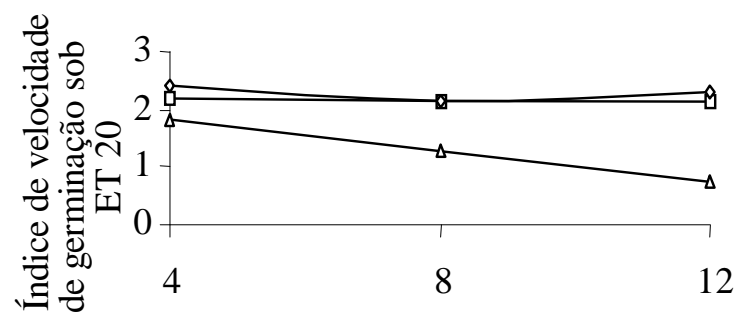

Tempo de embebição (dias)

$$
\neg-15 \text { graus } \rightarrow-25 \text { graus } \rightarrow-35 \text { graus }
$$

tendência crescente até à temperatura de $25^{\circ} \mathrm{C}$, com tendência a decrescer até a temperatura de $35^{\circ} \mathrm{C}$.

Os contrastes entre os resultados do índice de velocidade de germinação sob estresse térmico de $35^{\circ} \mathrm{C}$ relativos ao tratamento adicional (testemunha) e os métodos de condicionamento fisiológico das sementes de cafeeiro estão apresentados na Figura 5. De um modo geral, são observados valores baixos de índices, e no tempo de 8 dias de embebição a $15^{\circ} \mathrm{C}$ e $35^{\circ} \mathrm{C}$, houve $100 \%$ de mortalidade das sementes. Destacam-se, porém, os tratamentos das sementes por 12 dias de embebição a $15^{\circ} \mathrm{C}$ e $25^{\circ} \mathrm{C}$, que foram estatisticamente superiores à testemunha. Gulliver e Heydecker (1973) observaram que a temperatura tem influência sobre o processo de germinação tanto no que se refere à quantidade como velocidade, alterando a velocidade de absorção de água e também as reações bioquímicas que determinam o processo. Em relação à quantidade, ela decresce à medida que a temperatura cresce acima da ótima, ao contrário, a velocidade de germinação é acelerada com o aumento da temperatura, embora desorganize o processo, fazendo com que o número de sementes que conseguem completálo vá caindo rapidamente.

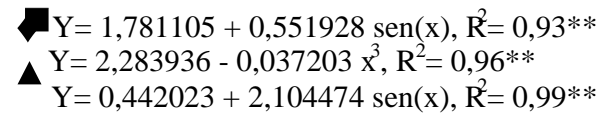

$\mathrm{b}$

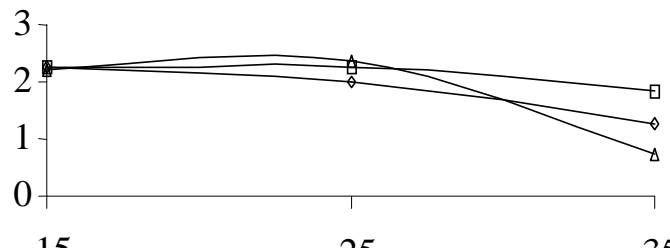

15 25 35

Temperatura de condicionamento

$$
\neg 4 \text { dias } \neg 8 \text { dias } \neg 12 \text { dias }
$$

FIGURA 3 - Índice de velocidade de germinação sob estresse térmico a $20^{\circ} \mathrm{C}$ (ET20) de sementes de cafeeiro submetidas ao condicionamento fisiológico em diferentes temperaturas e períodos de tempo. UFLA, Lavras-MG, 2003. 
$\mathrm{Y}=1,106493-0,430699 \operatorname{sen}(\mathrm{x}), \mathrm{R}^{2}=0,99 * *$ $Y=0,674438+0,029029 x^{3}, R^{2}=0,98 * *$

$\mathrm{Y}=0,816228-0,108595 \operatorname{sen}(\mathrm{x}), \mathrm{R}^{2}=0,95 * *$

a

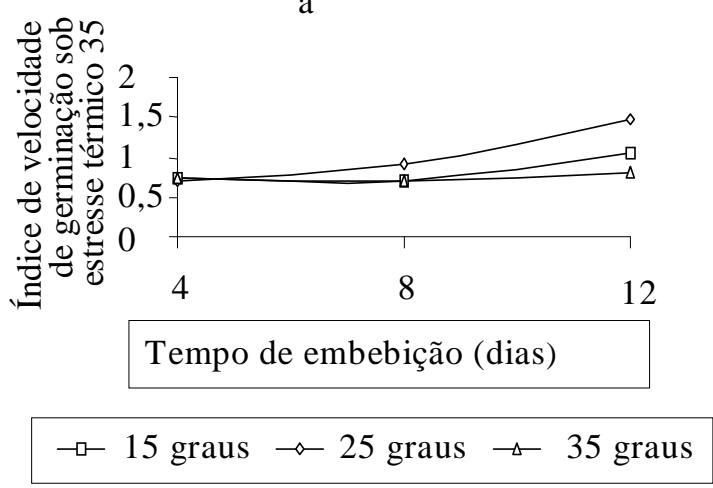

$\mathrm{Y}=0,760877-0,008174 \mathrm{x}, \mathrm{R}^{2}=0,99 * *$ A $\mathrm{Y}=0,744700-0,039274 \operatorname{Tan}(\mathrm{x}), \mathrm{R}^{2}=0,79 * *$

$\mathrm{b}$

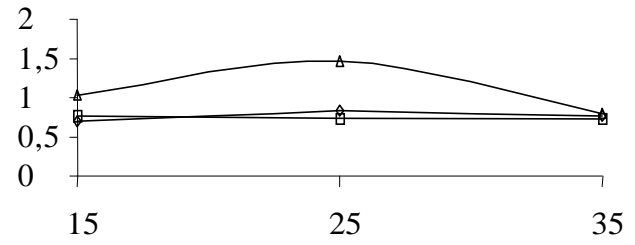

Temperatura de condicionamento

๑ 4 dias $\rightarrow-8$ dias $\rightarrow-12$ dias

(1) 4 dias $15^{\circ} \mathrm{C}$; (2) 4 dias $25^{\circ} \mathrm{C}$; (3) 4 dias $35^{\circ} \mathrm{C}$; (4) 8 dias $15^{\circ} \mathrm{C}$; (5) 8 dias $25^{\circ} \mathrm{C}$; (6) 8 dias $35^{\circ} \mathrm{C}$; (7) 12 dias $15{ }^{\circ} \mathrm{C}$; (8) 12 dias $25{ }^{\circ} \mathrm{C}$; (9) 12 dias $35{ }^{\circ} \mathrm{C}$; (10) testemunha; (**) significativo ao nível de $1 \%$ de probabilidade e (NS) não significativo.

FIGURA 4 - Índice de velocidade de germinação sob estresse térmico a $35^{\circ} \mathrm{C}$ de sementes de cafeeiro submetidas ao condicionamento fisiológico em diferentes temperaturas e períodos de tempo. UFLA, Lavras - MG, 2003.

\section{Análise enzimática}

Pelas Figuras 6 e 7 podem ser observados os padrões eletroforéticos do álcool desidrogenase (ADH) e da isocitrato desidrogenase (IDH) das sementes de cafeeiro submetidas a diferentes tempos e temperaturas de condicionamento fisiológico.Pela Figura 6, pode-se observar que a enzima álcool desidrogenase não apresentou atividade em sementes não-condicionadas (testemunha). Essa enzima atua no metabolismo anaeróbico de plantas, reduzindo o acetaldeído a etanol (VANTOAI et al., 1987). De acordo com Zang et al. (1994), a produção de acetaldeído durante o armazenamento pode acelerar a deterioração das sementes. Segundo os autores, o acetaldeído teve o maior efeito danoso, independente da umidade relativa e temperatura de armazenamento, enquanto o etanol causou deterioração de sementes, somente em condições de umidade relativa alta. É provável que a atividade da $\mathrm{ADH}$ revelada para os tratamentos esteja associada com um provável acúmulo de acetaldeído. Essa atividade da ADH pode ainda resultar em um suprimento adequado de ATP, via fermentação alcoólica. Dessa maneira, a via fermentativa torna-se fundamental para a manutenção da viabilidade da semente nessas condições (ALVES el al., 1997).
Ainda se observa que no tratamento em que as sementes foram submetidas a 4 dias de embebição a $15^{\circ} \mathrm{C}$, a atividade da $\mathrm{ADH}$ foi menos intensa em relação aos demais tratamentos. É provável que essa maior atividade da enzima nos demais tratamentos de condicionamento das sementes de cafeeiro esteja associada ao acumulo de produtos tóxicos formados pela rota anaeróbica que, possivelmente, foi ativada em função dos maiores tempos e/ou temperaturas em que as sementes foram submetidas à submersão. Nesse sentido, Alves et al. (1997) destacam que os produtos finais da fermentação (acetaldeído, etanol e ácido lático) são fitotóxicos, acumulam rapidamente e provocam distúrbios na organização celular, podendo levar a célula à morte, além da solubilização de lipídios das membranas citoplasmáticas e das organelas pela ação do etanol. Ainda, segundo esses autores, a anoxia causa grande aceleração no consumo de glicose, diminuindo drasticamente a sua disponibilidade para a célula. Em condições anaeróbicas, para a célula produzir a mesma quantidade de energia (ATP) que em condições aeróbicas, há necessidade de aumentar o consumo de glicose, pois a produção de ATP por molécula de glicose metabolizada é baixa (2 ATP/mol de glicose). 


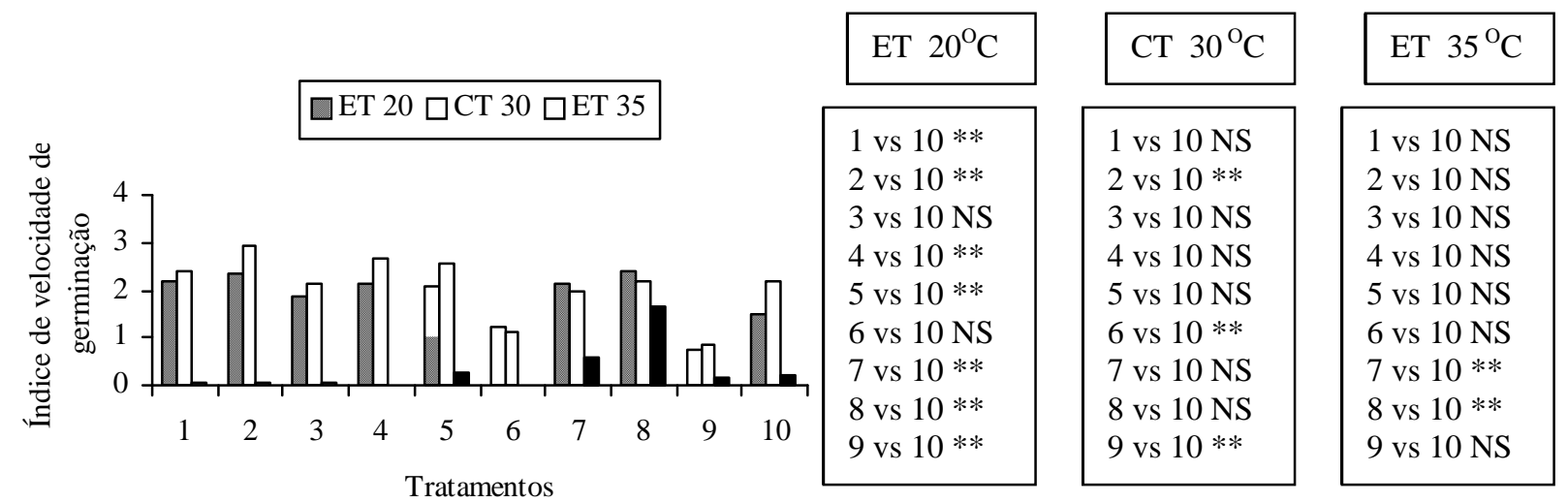

FIGURA 5 - Contrastes entre os resultados do índice de velocidade de germinação sob estresse térmico de 20 e $35^{\circ} \mathrm{C}$ e sob condições térmicas de $30^{\circ} \mathrm{C}$ relativos ao tratamento adicional (sementes não-condicionadas) e os métodos de condicionamento do esquema fatorial. UFLA, Lavras-MG, 2003.

(T) testemunha; (1) $4 \operatorname{dias} 15^{\circ} \mathrm{C}$; (2) 4 dias $25^{\circ} \mathrm{C}$; (3) $4 \operatorname{dias} 35^{\circ} \mathrm{C}$; (4) 8 dias $15^{\circ} \mathrm{C}$;

(5) 8 dias $25^{\circ} \mathrm{C}$; (6) 8 dias $35^{\circ} \mathrm{C}$; (7) 12 dias $15^{\circ} \mathrm{C}$; (8) 12 dias $25^{\circ} \mathrm{C}$; (9) 12 dias

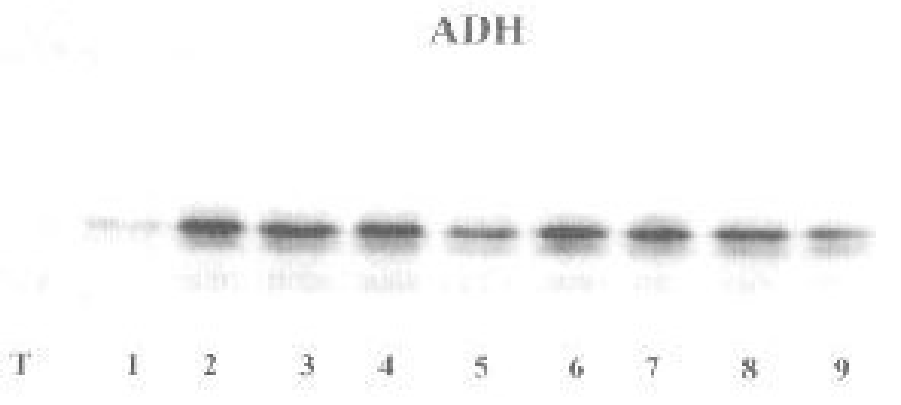

FIGURA 6 - Padrões isoenzimáticos de sementes de cafeeiro submetidas a diferentes tempos e temperaturas de condicionamento fisiológico, reveladas para a álcool desidrogenase (ADH). UFLA, Lavras - MG, 2003.

Com relação à isocitrato desidrogenase, observase pela Figura 7 que, da mesma maneira observada para a ADH (Figura 6), os padrões eletroforéticos dessa enzima foram bastante semelhantes nos diversos tratamentos de condicionamento. Essa enzima, ao contrário da $\mathrm{ADH}$, está relacionada com a respiração aeróbica, tendo importante função no ciclo de Krebs (GOODMAN e STUBER, 1987). Um aspecto que deve ser considerado é que, ao submeter as sementes a diferentes temperaturas e tempos de condicionamento, ocorre uma acele- ração na respiração e se não houver disponibilidade de oxigênio, pode ocorrer uma mudança da via normal de suprimento de ATP (via aeróbica) para uma via alternativa, que seria, no caso, a rota anaeróbica. Em função do maior tempo de condicionamento exigido para as sementes de cafeeiro em relação à maioria das espécies já estudadas, fica evidenciado, assim, que os cuidados com o suprimento adequado de oxigênio na solução de imersão das sementes são de grande importância. 


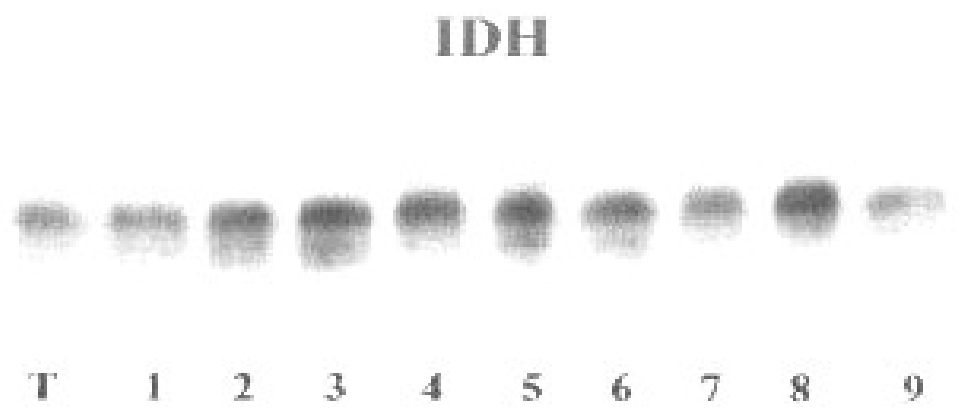

FIGURA 7 - Padrões isoenzimáticos de sementes de cafeeiro submetidas a diferentes tempos e temperaturas de condicionamento fisiológico, reveladas para a isocitrato desidrogenase (IDH). UFLA, Lavras - MG, 2003.

\section{CONCLUSÕES}

$\mathrm{O}$ condicionamento das sementes em água a 15 e $25^{\circ} \mathrm{C}$ promove maior germinação e vigor das sementes de cafeeiro em condições de estresse.

Os tempos de 8 e 12 dias de embebição propiciam os maiores incrementos no vigor das sementes de café.

$\mathrm{O}$ condicionamento à temperatura de $35^{\circ} \mathrm{C}$ não promove melhoria da qualidade fisiológica das sementes de café.

\section{REFERÊNCIAS BILBLIOGRÁFICAS}

ALFENAS, A. C. Eletroforese de proteínas e isoenzimas de fungos e essências florestais. Viçosa: UFV, 1991. $242 \mathrm{p}$.

ALVES, J. D.; OLIVEIRA, L. E. M.; GOMIDE, M. B. Fisiologia vegetal. Lavras: UFLA, 1997. 131 p. Apostila.

BRASIL. Ministério da Agricultura e da Reforma Agrária. Regras para análises de sementes. Brasília: SNDA/DNDV/CLAV, 1992. 365 p.

CAMARGO, R. Condicionamento fisiológico de sementes de cafeeiro (Coffea arabica L.). 1998. 108 f. Dissertação (Mestrado em Fitotecnia) - Universidade Federal de Lavras, Lavras, 1998.

GOODMAN, M. M.; STUBER, C. W. Maize. In: TANKSLEY, S. D.; ORTON, T. L. Isozymes in plant genetics and breeding: part B. Amsterdam: Elsevier, 1987. p. 1-33.
GULLIVER, R. L.; HEYDECKER, W. Establishment of seedlings in changeable environment. In: HEYDECKER, W. (Ed.). Seed ecology. London: Butterworth, 1973. p. 433-462.

HEYDECKER, W.; HIGGINS, J.; TURNER, I. J. Invigoration of seeds? Seed Science and Technology, Zurich, v. 3, n. 3, p. 881-888, 1975.

KHAN, A. A.; BRAUM, J. W.; TAO, K. L.; MILLIER, W. F.; BENSIN, R. F. New methods for maintaining seed vigor and improving performance. Journal of Seed Technology, Lansing, v. 1, n. 2, p. 33-57, 1976.

KHAN, A. A.; PECK, N. H.; SAMIMY, C. Seed osmoconditioning, physiological and biochemical changes. Israel Journal of Botany, Jerusalem, v. 29, n. 1/4, p. 133-144, 1980/81.

LABOURIAU, L. G. A germinação das sementes. Washington: OEA, 1983.

LIMA, W. A. A. Condicionamento fisiológico, germinação e vigor de sementes de café (Coffea arabica L.). 1999. 69 f. Dissertação (Mestrado em Fitotecnia) Universidade Federal de Viçosa, Viçosa, 1999.

MAGUIRRE, J. D. Speed of germination: aid seedling emergence and vigor. Crop Science, Madison, v. 2, n. 2, p. 176-177, Mar./Apr. 1962.

NASCIMENTO, W. M. Condicionamento osmótico de sementes de hortaliças: potencialidades e implicações. 
Horticultura Brasileira, Brasília, v. 16, n. 2, p. 106109, 1998.

VANTOAI, T. T.; FAUSEY, N. R.; McDONALD JUNIOR, M. B. Anaerobic metabolism enzymes as markers of flooding stress in maize seeds. Plant and Soil, New York, v. 102, n. 1, p. 33-39, 1987.

WENT, F. W. The experimental control of plant growth. New York: The Ronald, 1957. 304 p.
(Chronica Botanic - International Biological and Agricultural Series, 17).

ZHANG, M.; MAEDA, Y.; FURIHATA, Y.; NAKAMAR, Y.; ESASHI, Y. A mechanism of seed deteriration in relation to the volatile compounds evolved by dry seeds themselves. Seed Science Research, Wallingford, v. 4, p. 49-56, Mar. 1994. 